\title{
The Influence of Minimal Misalignment on the Repeatability of PET Images Examined by the Repositioning of Point Sources
}

\author{
Akira Maebatake $^{1}$, Keishin Morita ${ }^{1}$, Go Akamatsu ${ }^{2}$, Yuji Tsutsui ${ }^{3}$, Kazuhiko Himuro ${ }^{3}$, Shingo Baba ${ }^{4}$, and Masayuki Sasaki ${ }^{1}$ \\ ${ }^{1}$ Division of Medical Quantum Science, Department of Health Sciences, Graduate School of Medical Sciences, Kyushu University, \\ Fukuoka, Japan; ${ }^{2}$ National Institute of Radiological Sciences, National Institutes for Quantum and Radiological Science and \\ Technology, Chiba, Japan; ${ }^{3}$ Division of Radiology, Department of Medical Technology, Kyushu University Hospital, Fukuoka, Japan; \\ and ${ }^{4}$ Department of Clinical Radiology, Graduate School of Medical Sciences, Kyushu University, Fukuoka, Japan
}

\begin{abstract}
We aimed to evaluate the influence of minimal misalignment of a hot spot on the repeatability of PET images using repositioning of point sources. Methods: Point sources with an inner diameter of $1 \mathrm{~mm}$ were made with $1 \mu \mathrm{L}$ of ${ }^{18} \mathrm{~F}$ solution. Seven point sources were placed on the $x$-axis in the field of view. For fixed-position imaging, PET data were acquired for $10 \mathrm{~min}$ 5 times serially. For variable-position imaging, PET data were acquired for $10 \mathrm{~min}$ each with the point sources placed at 0 , \pm 0.5 , and $\pm 1.0 \mathrm{~mm}$ in the $x$-axis direction. The data were reconstructed using ordered-subsets expectation maximization (OSEM) and OSEM plus point-spread function (PSF). The image matrix was $128 \times 128,200 \times 200,256 \times 256,400 \times 400$, and $512 \times 512$ pixels. The normalized maximum count (rMax), the coefficient of variance $\left(\mathrm{CV}_{\max }\right)$, and the full width at half maximum were analyzed. Results: The hot spots on OSEM images far from the center became faint and broad, whereas those on OSEM+PSF images became small and dense. Although rMax was overestimated at the 5-cm position on OSEM images, rMax at other positions was overestimated on OSEM+PSF images with a matrix of at least $256 \times 256$. rMax showed a similar pattern in fixed- and variable-position images. $\mathrm{CV}_{\text {max }}$ in fixedposition OSEM images was less than $2 \%$, irrespective of matrix size. In contrast, $\mathrm{CV}_{\max }$ in variable-position images was higher than in fixed-position images. $\mathrm{CV}_{\max }$ was higher for OSEM+PSF images than for OSEM images. The full width at half maximum increased at positions far from the center on OSEM images but was stable at all positions on OSEM+PSF images. Conclusion: The repeatability of the small hot spot was affected by the minimal misalignment, especially on OSEM+PSF images. Precise positioning is necessary if PET is to be used as a biomarker. Professionals should recognize that PSF correction worsens the repeatability of the small hot spot although improving the spatial resolution of PET images.
\end{abstract}

Key Words: PET/CT; repeatability; repositioning; point-spread function

J Nucl Med Technol 2019; 47:55-59

DOI: 10.2967/jnmt.118.208835

Received Jul. 8, 2018; revision accepted Aug. 23, 2018.

For correspondence or reprints contact: Masayuki Sasaki, Division of Medical Quantum Science, Department of Health Sciences, Graduate School of Medical Sciences, Kyushu University, 3-1-1 Maidashi, Higashi-ku, Fukuoka 812-8582, Japan.

E-mail: msasaki@hs.med.kyushu-u.ac.jp

Published online Nov. 9, 2018.

COPYRIGHT (C) 2019 by the Society of Nuclear Medicine and Molecular Imaging.
$\mathbf{P}$ detection of tumors, staging, and monitoring of the responses to therapy and for prognostic stratification of various malignant tumors (1-4). Evaluation of ${ }^{18} \mathrm{~F}$-FDG PET/ CT images is often based on visual assessment and semiquantitative values (5-7). Thus, the quality and quantitative accuracy of PET images are important. However, numerous factors (e.g., acquisition time, patient body weight, radiopharmaceutical dose, and system characteristics) are known to affect quantification of PET images (8-10). Two essential requirements for quantification are repeatability and reproducibility (11). Repeatability is defined as consistency in the results obtained for the same patient when examined multiple times on the same system. Reproducibility is defined as consistency in the results for the same patient when examined on different systems in different institutions. Some studies have reported the repeatability and reproducibility of PET image quantification $(12,13)$. Schwartz et al. evaluated the repeatability of SUV based on statistical fluctuations using a cylindric ${ }^{68} \mathrm{Ge}$ phantom and the flangeless Esser phantom filled with ${ }^{18}$ F-FDG (14). Doot et al. assessed repeatability and reproducibility using a National Electrical Manufacturers Association NU-2 image-quality phantom that was removed and repositioned in the center of field of view, to approximately $\pm 2 \mathrm{~mm}$ accuracy, 20 times, with 3 different PET scanners (15). They reported that the variation in the recovery coefficient using the maximum count was $3.6 \%$. The recent advancement of PET/CT technology has led to increasing use of ${ }^{18} \mathrm{~F}-\mathrm{FDG}$ PET/CT in the evaluation of subcentimeter lesions $(16,17)$. Repeatability is thus of increasing importance in the quantitative evaluation of small lesions; however, minimal misalignment, which cannot be avoided —even with careful repositioningmay have an impact on repeatability. Furthermore, a change in the physical constitution of the patient during clinical progress may change the positional relationship. Most studies have not examined the influence of minimal misalignment $(\leq 2 \mathrm{~mm})$ on the quantification of PET images.

The aim of the present study was to evaluate the influence of minimal misalignment of the hot spot on the repeatability of PET images using the repositioning of point sources. 


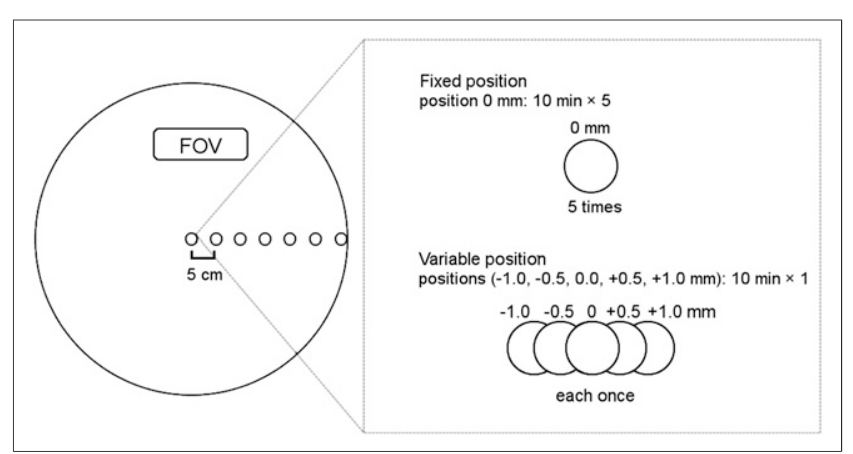

FIGURE 1. Setting of point sources. Seven point sources were placed on $x$-axis (interval, $5 \mathrm{~cm}$ ). For fixed-position images, data were acquired for $10 \mathrm{~min}, 5$ times serially. For variable-position images, data were acquired for $10 \mathrm{~min}$ each with point sources at $0, \pm 0.5$, and $\pm 1.0 \mathrm{~mm}$ in $x$-axis direction to simulate minimum of repositioning.

\section{MATERIALS AND METHODS}

\section{Point Sources}

The point sources consisted of a glass capillary (Microcaps; Drummond Scientific Co.) $51.8 \mathrm{~mm}$ in length and $0.99 \mathrm{~mm}$ in inner diameter. A glass capillary was filled with $1 \mu \mathrm{L}$ of ${ }^{18} \mathrm{~F}$ solution (radioactivity, $76.5 \mathrm{MBq} / \mathrm{mL}$ ). The length of the point source was approximately $1 \mathrm{~mm}$. The radioactivity of the point source was measured using an automatic well $\gamma$-counter (AccuFLEX $\gamma 7001$; Hitachi Aloka Medical, Ltd.) and was used as a reference value (true radioactivity; $\left.\mathrm{C}_{\text {true }, i}, i=1-7\right)$. The mean $\mathrm{C}_{\text {true }}$ of the 7 sources was $29.0 \pm 1.69 \mathrm{kBq}$.

\section{Positioning of Point Sources}

The 7 point sources were placed on the $x$-axis (intervals of $5 \mathrm{~cm}$ ) in the field of view (Fig. 1). The coordinates of the innermost point source in the field of view were $0 \mathrm{~mm}$ and $0 \mathrm{~mm}$, and the coordinates of the outermost point source were $30 \mathrm{~mm}$ and $0 \mathrm{~mm}$. For the fixed-position images, data were acquired for $10 \mathrm{~min}, 5$ times serially. For the variable-position images, the point sources were placed $\pm 0.5 \mathrm{~mm}$ and $\pm 1.0 \mathrm{~mm}$ in the $x$-axis direction to simulate the minimum of repositioning. Data were acquired for $10 \mathrm{~min}$ each at the above 5 positions by using an automatic stage ALS-604-E1P (Chuo Precision Industrial Co., Ltd.). The accuracy of the movement distance of the point source was $\pm 0.015 \mathrm{~mm}$.

\section{Data Acquisition}

PET data were acquired using a PET/CT scanner (Biograph mCT; Siemens Healthcare). This PET scanner covers an axial field of view of $16.2 \mathrm{~cm}$ in length and a transaxial field of view of $70 \mathrm{~cm}$ in diameter and consists of a total of 24,336 lutetium orthosilicate detector elements (dimensions, $4 \times 4 \times 20 \mathrm{~mm}$ ). The coincidence time window was $4.1 \mathrm{~ns}$. The PET data were acquired in 3-dimensional list mode for $10 \mathrm{~min}$. The full width at half maximum (FWHM) at 1 and $10 \mathrm{~cm}$ is 5.9 and $6.0 \mathrm{~mm}$, respectively, in standard processing $(256 \times 256)$ and 4.4 and $4.9 \mathrm{~mm}$, respectively, in high-resolution processing $(400 \times 400)$.

\section{Image Reconstruction}

The PET images were reconstructed using ordered-subsets expectation maximization (OSEM) alone and with point-spread function (PSF) correction. The parameters for both OSEM and OSEM+PSF were 3 iterations and 24 subsets. No postsmoothing filter was used for either algorithm. The image matrix was $128 \times$ $128,200 \times 200,256 \times 256,400 \times 400$, and $512 \times 512$ pixels (pixel sizes, 6.36, 4.07, 3.18, 2.04, and $1.59 \mathrm{~mm}$, respectively). The slice thickness of the PET image was $5 \mathrm{~mm}$. The CT data for attenuation correction were obtained by a whole-body CT scan $(120 \mathrm{kV}$, $100 \mathrm{~mA}, 0.5-\mathrm{s}$ tube rotation, and 5-mm slice). Scatter correction was performed using the model-based method.

\section{Data Analysis}

We placed a circular region of interest $\left(\mathrm{ROI}_{i}, i=1-7\right)$ to include the whole radioactivity of each point source. The maximum radioactivity of the point source $i$ was measured as $\mathrm{C}_{\max , i}$. Because the radioactivity of the 7 point sources was not completely equal, $\mathrm{C}_{\max , i}$ was normalized by $\mathrm{C}_{\text {true }, i}$ as $\operatorname{rMax}_{i}$ :

$$
\operatorname{rMax}_{i}=\mathrm{C}_{\mathrm{max}, i} / \mathrm{C}_{\text {true }, i}
$$

The variation of $\operatorname{rMax}_{i}$ was evaluated by the coefficient of variance $\left(\mathrm{CV}_{\max }\right)$, which was calculated as follows:

$$
\mathrm{CV}_{\max , i}=\mathrm{SD} \text { of } \operatorname{rMax}_{i} / \text { mean of } \operatorname{rMax}_{i} \times 100(\%) \text {. }
$$

The FWHM of the $x$-direction on point source $i$ was calculated as $\mathrm{FWHM}_{i}$, according to the requirements for NU-2 (18). The maximum pixel value and its 2 nearest-neighbor points were used for a parabolic fitting. The position at half the maximum value was determined by linear interpolation between adjacent pixels. The pixel size was set to $6.36,4.07,3.18,2.04$, and $1.59 \mathrm{~mm}$.

\section{RESULTS}

Figure 2 shows images of the point source obtained at a fixed position and using OSEM and OSEM+PSF. The shape and density of the hot spots differed according to the position and the matrix size. The images of point sources far from the center became faint and broad. In images with a large matrix, the point sources were dense and sharp. In comparison to OSEM images, the hot spots on OSEM+PSF images were small and dense. Figure 3 shows the point source in variable-position images with a $400 \times 400$ matrix that were obtained using OSEM and OSEM+PSF. The hot spots far from the center also appeared faint and broad, similar to the 


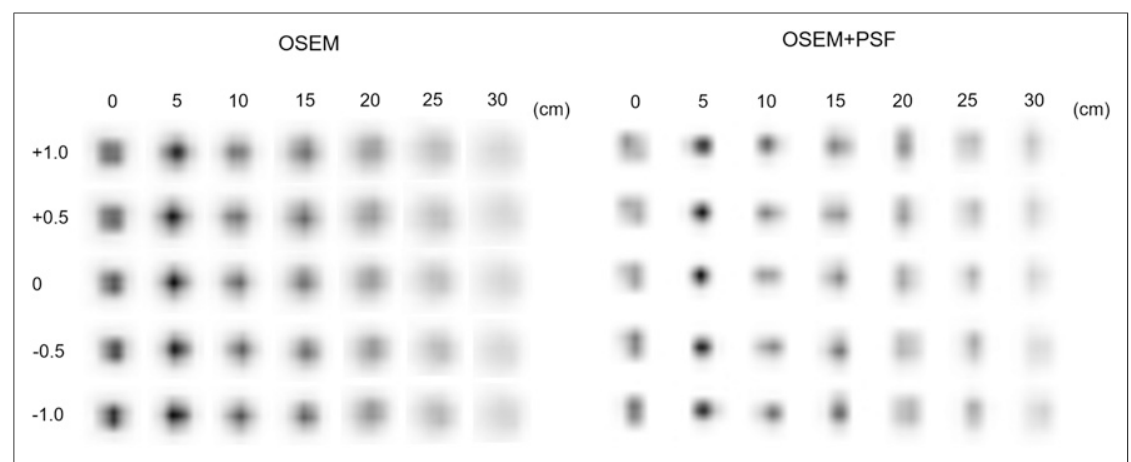

FIGURE 3. Images of point sources at variable positions reconstructed by OSEM and OSEM+PSF with $400 \times 400$ matrix. Density and shape of point sources differed among positions.

fixed-position images. The density and shape of the hot spots differed according to the position of the point source. In comparison to OSEM images, the hot spots on OSEM+PSF images were small and dense.

Figure 4 shows $\mathrm{rMax}_{i}$ for both the fixed and the variable positions. On OSEM images with a matrix of no more than $200 \times 200$, the $\mathrm{rMax}_{i}$ of most point sources at both positions was underestimated (range, $0.58-0.13$ ). In contrast, $\mathrm{rMax}_{i}$ was overestimated as 1.37 at the $5-\mathrm{cm}$ position in images with a matrix of $256 \times 256$ or more. $\operatorname{rMax}_{2}$ was highest at $5 \mathrm{~cm}$ and gradually decreased as the distance from the center increased. $\operatorname{rMax}_{i}$ in the fixed and variable positions showed a similar pattern. Table 1 shows $\mathrm{CV}_{\text {max }, i}$ for fixed- and variable-position OSEM images. In the fixed position, $\mathrm{CV}_{\text {max }, i}$ was less than $2 \%$, irrespective of the matrix size (range, $0.28 \%-1.73 \%$ ). In contrast, $\mathrm{CV}_{\text {max }, i}$ was higher for variable-position images than for fixed-position images (range, $0.64 \%-12.5 \%$ ).

\section{DISCUSSION}

$\operatorname{rMax}_{i}$ was higher for OSEM+PSF images than for OSEM images (Fig. 4) and was highest at $5 \mathrm{~cm}$ with a matrix of $256 \times 256$ or more. $\mathrm{rMax}_{i}$ showed a similar pattern in fixed and variableposition images. Table 2 shows the $\mathrm{CV}_{\text {max }, i}$ of OSEM+PSF images. $\mathrm{CV}_{\text {max }, i}$ was higher for PSF images than for OSEM images. In fixed-position images, $\mathrm{CV}_{\max , i}$ was no more than $2.76 \%$ irrespective of matrix size (range, $0.33 \%-2.76 \%$ ). In contrast, $\mathrm{CV}_{\max , i}$ was higher for variableposition images than for fixed-position images (range, $0.92 \%-31.7 \%$ ). $\mathrm{CV}_{\max , i}$ was high irrespective of matrix size.

Figure 5 shows the $\mathrm{FWHM}_{i}$ of the fixed- and variableposition images. $\mathrm{FWHM}_{i}$ increased at positions far from the center in OSEM images, especially those with a matrix of $128 \times 128$. In contrast, the $\mathrm{FWHM}_{i}$ of the OSEM+PSF images was stable at all positions. $\mathrm{FWHM}_{i}$ was large in images with a small matrix. The $\mathrm{FWHM}_{i}$ of the fixed- and variable-position images showed a similar pattern.

Through simulated repositioning, we examined the influence of minimal misalignment on the repeatability of PET images. The maximum counts were different and varied according to position and matrix size. The degree of variation for variable-position images was larger than for fixed-position images. In particular, the degree of variation was higher for OSEM+PSF images than for OSEM images. The FWHM of OSEM images increased at positions far from the center, whereas the FWHM of OSEM+PSF images was stable at all positions.

The intensity and shape of pointsource images differed according to position and matrix size. Additionally, $\mathrm{CV}_{\text {max }, i}$ was higher for variable-position images than for fixed-position images. Measurements of the radioactivity of a small region are strongly affected by the partial-volume effect (19). Mansor et al. reported that the precision of $\mathrm{SUV}_{\max }$ was affected by phantom repositioning in a study that used hot spheres of $\leq 15 \mathrm{~mm}$ in diameter (20). Furthermore, Adams et al. reported that the measured PET count varied and that there was a relationship between the alignment of the hot spot and the pixels (21). The PET count varied and, because of the partial-volume effect, was underestimated if the hot spot was between certain pixels (19). The alignment of the point
FIGURE 4. $\mathrm{rMax}_{, i}$ at both fixed and variable positions on OSEM and OSEM+PSF images. At both positions, $\operatorname{rMax}_{i}$ decreased at positions far from center. $\mathrm{rMax}_{i}$ was higher on OSEM+PSF images than on OSEM images. 
TABLE 1

$\mathrm{CV}_{\text {max }, i}$ on OSEM Images

\begin{tabular}{|c|c|c|c|c|c|c|c|}
\hline \multirow[b]{2}{*}{ Matrix } & \multicolumn{7}{|c|}{ Position (cm) } \\
\hline & 0 & 5 & 10 & 15 & 20 & 25 & 30 \\
\hline \multicolumn{8}{|l|}{$128 \times 128$} \\
\hline $\begin{array}{l}\text { Fixed } \\
\text { Variable }\end{array}$ & $\begin{array}{l}0.39 \% \\
7.06 \%\end{array}$ & $\begin{array}{l}0.31 \% \\
0.70 \%\end{array}$ & $\begin{array}{l}0.31 \% \\
3.68 \%\end{array}$ & $\begin{array}{l}0.56 \% \\
4.90 \%\end{array}$ & $\begin{array}{l}1.30 \% \\
12.5 \%\end{array}$ & $\begin{array}{c}1.03 \% \\
11.1 \%\end{array}$ & $\begin{array}{l}0.52 \% \\
5.40 \%\end{array}$ \\
\hline \multicolumn{8}{|l|}{$200 \times 200$} \\
\hline $\begin{array}{l}\text { Fixed } \\
\text { Variable }\end{array}$ & $\begin{array}{l}0.39 \% \\
7.06 \%\end{array}$ & $\begin{array}{l}0.49 \% \\
5.84 \%\end{array}$ & $\begin{array}{l}0.31 \% \\
3.68 \%\end{array}$ & $\begin{array}{l}0.49 \% \\
0.64 \%\end{array}$ & $\begin{array}{l}0.32 \% \\
7.80 \%\end{array}$ & $\begin{array}{l}1.04 \% \\
5.61 \%\end{array}$ & $\begin{array}{l}1.02 \% \\
1.86 \%\end{array}$ \\
\hline \multicolumn{8}{|l|}{$256 \times 256$} \\
\hline $\begin{array}{l}\text { Fixed } \\
\text { Variable }\end{array}$ & $\begin{array}{l}0.69 \% \\
10.9 \%\end{array}$ & $\begin{array}{l}0.67 \% \\
3.91 \%\end{array}$ & $\begin{array}{l}0.46 \% \\
7.68 \%\end{array}$ & $\begin{array}{l}0.75 \% \\
6.35 \%\end{array}$ & $\begin{array}{l}0.41 \% \\
5.48 \%\end{array}$ & $\begin{array}{l}0.88 \% \\
1.14 \%\end{array}$ & $\begin{array}{l}1.73 \% \\
3.17 \%\end{array}$ \\
\hline \multicolumn{8}{|l|}{$400 \times 400$} \\
\hline $\begin{array}{l}\text { Fixed } \\
\text { Variable }\end{array}$ & $\begin{array}{l}0.49 \% \\
9.13 \%\end{array}$ & $\begin{array}{l}0.67 \% \\
3.91 \%\end{array}$ & $\begin{array}{l}0.46 \% \\
5.96 \%\end{array}$ & $\begin{array}{l}0.98 \% \\
2.58 \%\end{array}$ & $\begin{array}{l}0.87 \% \\
2.38 \%\end{array}$ & $\begin{array}{l}0.84 \% \\
1.60 \%\end{array}$ & $\begin{array}{l}1.18 \% \\
3.29 \%\end{array}$ \\
\hline \multicolumn{8}{|l|}{$512 \times 512$} \\
\hline $\begin{array}{l}\text { Fixed } \\
\text { Variable }\end{array}$ & $\begin{array}{l}0.28 \% \\
4.81 \%\end{array}$ & $\begin{array}{l}0.67 \% \\
3.91 \%\end{array}$ & $\begin{array}{l}0.46 \% \\
6.31 \%\end{array}$ & $\begin{array}{l}0.85 \% \\
1.71 \%\end{array}$ & $\begin{array}{l}0.80 \% \\
2.07 \%\end{array}$ & $\begin{array}{l}0.31 \% \\
0.75 \%\end{array}$ & $\begin{array}{l}0.68 \% \\
2.46 \%\end{array}$ \\
\hline
\end{tabular}

source in a pixel is considered to influence the height and shape of the PSF.

The $\mathrm{CV}_{\text {max }, i} \mathrm{~S}$ values of the fixed-position images were less than $3 \%$ in our study. Schwartz et al. reported statistical variation on the order of $5 \%$ (14). Thus, the variation in the maximum count of fixed-position images in our study was thought to stem from statistical variation. On the other hand, the $\mathrm{CV}_{\max , i}$ of the variable-position OSEM images ranged from $0.64 \%$ to $12.5 \%$ in the present study. Some patient studies have found a test-retest SUV variability of approximately $10 \%-15 \%(13,22,23)$. Doot et al. found SUV variability without any biologic variability in a repositioning study (imaging protocol variation, $<10 \%$ ) using an NU-2 image-quality phantom (15). Thus, the $\mathrm{CV}_{\max , i}$ of the variable-position images is considered an important exacerbating factor for repeatability.

$\mathrm{rMax}_{i}$ and $\mathrm{CV}_{\max }$ were higher for OSEM+PSF images than for OSEM images. PSF correction has been used to improve the spatial resolution of PET images. $\mathrm{FWHM}_{i}$ increased at positions far from the center of OSEM images but was stable at all positions for PSF images. Murata et al. also showed that PSF correction reduced the dependency of spatial resolution on position (24). PSF correction has been reported to result in overestimation due to edge artifacts in small regions and is therefore a problem for quantification (25). We previously reported that edge artifacts were observed as a sharp peak at the center of small hot spheres (26). Zhang et al. found that edge artifacts were unclear in areas of low radioactivity (27). Thus, the degree of overestimation due to edge artifacts varied with level of radioactivity. Furthermore, PSF correction was found to increase SUV variability in a phantom study (20). Although PSF correction improved PET image quality, OSEM+PSF images are considered to increase the variation of $\operatorname{rMax}_{i}$ and $\mathrm{CV}_{\max , i}$ in comparison to OSEM images.

The present study has several limitations. First, the precise positional relationship between the point source and the pixel could not be clarified. A simulation study may solve this problem. Second, FWHM was estimated by parabolic fitting based on the nearest pixel values and thus might be

TABLE 2

$\mathrm{CV}_{\text {max }, i}$ on OSEM+PSF Images

\begin{tabular}{|c|c|c|c|c|c|c|c|}
\hline \multirow[b]{2}{*}{ Matrix } & \multicolumn{7}{|c|}{ Position (cm) } \\
\hline & 0 & 5 & 10 & 15 & 20 & 25 & 30 \\
\hline \multicolumn{8}{|l|}{$128 \times 128$} \\
\hline $\begin{array}{l}\text { Fixed } \\
\text { Variable }\end{array}$ & $\begin{array}{l}0.44 \% \\
9.89 \%\end{array}$ & $\begin{array}{l}0.84 \% \\
0.92 \%\end{array}$ & $\begin{array}{l}0.56 \% \\
10.4 \%\end{array}$ & $\begin{array}{l}0.47 \% \\
7.09 \%\end{array}$ & $\begin{array}{l}0.33 \% \\
6.83 \%\end{array}$ & $\begin{array}{l}1.22 \% \\
18.7 \%\end{array}$ & $\begin{array}{l}1.39 \% \\
5.76 \%\end{array}$ \\
\hline \multicolumn{8}{|l|}{$200 \times 200$} \\
\hline $\begin{array}{l}\text { Fixed } \\
\text { Variable }\end{array}$ & $\begin{array}{l}0.46 \% \\
9.89 \%\end{array}$ & $\begin{array}{r}0.85 \% \\
10.21 \%\end{array}$ & $\begin{array}{l}0.50 \% \\
10.4 \%\end{array}$ & $\begin{array}{l}0.57 \% \\
7.09 \%\end{array}$ & $\begin{array}{l}0.30 \% \\
6.64 \%\end{array}$ & $\begin{array}{l}1.09 \% \\
18.7 \%\end{array}$ & $\begin{array}{r}1.32 \% \\
10.89 \%\end{array}$ \\
\hline \multicolumn{8}{|l|}{$256 \times 256$} \\
\hline $\begin{array}{l}\text { Fixed } \\
\text { Variable }\end{array}$ & $\begin{array}{l}1.55 \% \\
25.1 \%\end{array}$ & $\begin{array}{l}0.73 \% \\
5.47 \%\end{array}$ & $\begin{array}{l}0.84 \% \\
31.7 \%\end{array}$ & $\begin{array}{l}1.00 \% \\
6.97 \%\end{array}$ & $\begin{array}{l}1.04 \% \\
5.66 \%\end{array}$ & $\begin{array}{l}1.99 \% \\
8.85 \%\end{array}$ & $\begin{array}{l}0.92 \% \\
22.1 \%\end{array}$ \\
\hline \multicolumn{8}{|l|}{$400 \times 400$} \\
\hline $\begin{array}{l}\text { Fixed } \\
\text { Variable }\end{array}$ & $\begin{array}{l}1.27 \% \\
18.8 \%\end{array}$ & $\begin{array}{l}0.73 \% \\
5.47 \%\end{array}$ & $\begin{array}{l}0.49 \% \\
16.3 \%\end{array}$ & $\begin{array}{c}1.48 \% \\
16.6 \%\end{array}$ & $\begin{array}{l}0.69 \% \\
21.0 \%\end{array}$ & $\begin{array}{l}2.76 \% \\
14.8 \%\end{array}$ & $\begin{array}{l}1.39 \% \\
13.9 \%\end{array}$ \\
\hline \multicolumn{8}{|l|}{$512 \times 512$} \\
\hline $\begin{array}{l}\text { Fixed } \\
\text { Variable }\end{array}$ & $\begin{array}{l}0.39 \% \\
12.4 \%\end{array}$ & $\begin{array}{l}0.73 \% \\
5.47 \%\end{array}$ & $\begin{array}{l}0.41 \% \\
13.7 \%\end{array}$ & $\begin{array}{c}1.48 \% \\
12.3 \%\end{array}$ & $\begin{array}{l}1.04 \% \\
10.3 \%\end{array}$ & $\begin{array}{l}0.88 \% \\
5.33 \%\end{array}$ & $\begin{array}{l}1.03 \% \\
12.6 \%\end{array}$ \\
\hline
\end{tabular}




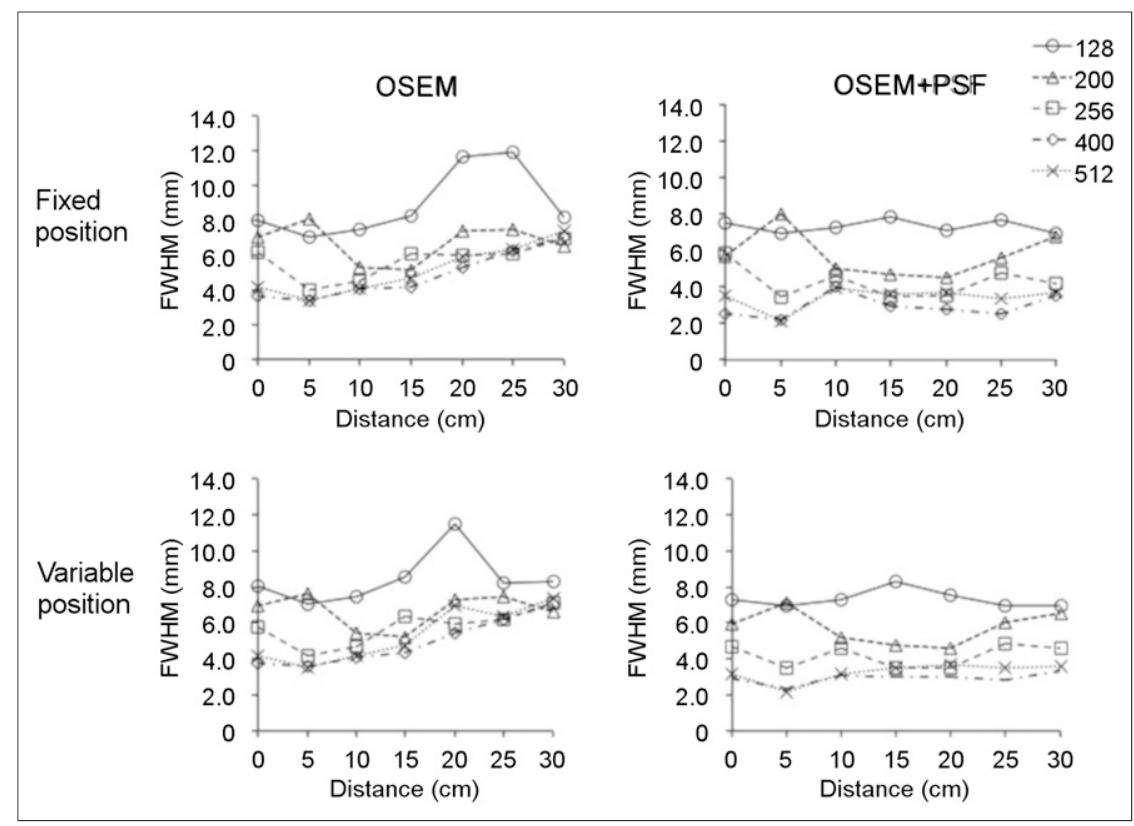

FIGURE 5. FWHM,$i$ at both fixed and variable positions on OSEM and OSEM +PSF images. $\mathrm{FWHM}_{, i}$ increased at positions far from center on OSEM images. $\mathrm{FWHM}_{, i}$ of OSEM+PSF images was stable at all positions.

overestimated in images with large pixels. Third, we evaluated the repeatability of PET/CT images using a point source in air. Because lesions in the human body are usually in areas with physical uptake of radioactivity, a further study that also investigates background radioactivity should be performed.

\section{CONCLUSION}

The repeatability of images showing small hot spots was affected by minimal misalignment $(\leq 2 \mathrm{~mm})$, especially when the images were reconstructed with PSF. Positioning is considered important if PET is to be used as a reliable biomarker. Professionals should recognize that PSF correction deteriorates the repeatability of small hot spots on PET images although improving the spatial resolution.

\section{DISCLOSURE}

No potential conflict of interest relevant to this article was reported.

\section{REFERENCES}

1. Rohren EM, Turkington TG, Coleman RE. Clinical applications of PET in oncology. Radiology. 2004;231:305-332.

2. Hicks RJ. Role of ${ }^{18}$ F-FDG PET in assessment of response in non-small cell lung cancer. J Nucl Med. 2009;50(suppl 1):31S-42S.

3. Fischer B, Lassen U, Mortensen J, et al. Preoperative staging of lung cancer with combined PET-CT. N Engl J Med. 2009;361:32-39.

4. van Elmpt W, Ollers M, Dingemans AM, Lambin P, De Ruysscher D. Response assessment using ${ }^{18} \mathrm{~F}-\mathrm{FDG}$ PET early in the course of radiotherapy correlates with survival in advanced stage non-small cell lung cancer. J Nucl Med. 2012;53:1514-1520.

5. Young H, Baum R, Cremerius U, et al. Measurement of clinical and subclinical tumor response using $\left[{ }^{18} \mathrm{~F}\right]$-fluorodeoxyglucose and positron emission tomography: review and 1999 EORTC recommendations. European Organization for Research and Treatment of Cancer (EORTC) PET Study Group. Eur J Cancer. 1999;35:1773-1782.
6. Wahl RL, Jacene H, Kasamon Y, Lodge MA. From RECIST to PERCIST: evolving considerations for PET response criteria in solid tumors. J Nucl Med. 2009;50(suppl 1):122S-150S.

7. Weber WA, Petersen V, Schmidt B, et al. Positron emission tomography in non-small-cell lung cancer: prediction of response to chemotherapy by quantitative assessment of glucose use. J Clin Oncol. 2003;21:2651-2657.

8. Keyes JW Jr. SUV: standard uptake or silly useless value? J Nucl Med. 1995;36:1836-1839.

9. Westerterp M, Pruim J, Oyen W, et al. Quantification of FDG PET studies using standardised uptake values in multi-centre trials: effects of image reconstruction, resolution and ROI definition parameters. Eur J Nucl Med Mol Imaging. 2007;34:392-404.

10. Boellaard R. Standards for PET image acquisition and quantitative data analysis. J Nucl Med. 2009; 50(suppl 1):11S-20S.

11. Boellaard R, Delgado-Bolton R, Oyen WJ, et al. FDG PET/CT: EANM procedure guidelines for tumor imaging: version 2.0. Eur J Nucl Med Mol Imaging. 2015;42:328-354.

12. Minn H, Zasadny KR, Quint LE, Wahl RL. Lung cancer: reproducibility of quantitative measurements for evaluating 2-[F-18]-fluoro-2-deoxy-D-glucose uptake at PET. Radiology. 1995;196:167-173.

13. Velasquez LM, Boellaard R, Kollia G, et al. Repeatability of ${ }^{18} \mathrm{~F}$-FDG PET in a multicenter phase 1 study of patients with advanced gastrointestinal malignancies. J Nucl Med. 2009;50:1646-1654.

14. Schwartz J, Humm JL, Gonen M, et al. Repeatability of SUV measurements in serial PET. Med Phys. 2011;38:2629-2638.

15. Doot RK, Scheuermann JS, Christian PE, Karp JS, Kinahan PE. Instrumentation factors affecting variance and bias of quantifying tracer uptake with PET/CT. Med Phys. 2010;37:6035-6046.

16. Yoon HJ, Lee JJ, Kim YK, Kim SE. FDG-PET/CT is superior to enhanced CT in detecting recurrent subcentimeter lesions in the abdomeninopelvic cavity in colorectal cancer. Nucl Med Mol Imaging. 2011;45:132-138.

17. Kunawudhi A, Pak-art R, Keelawat S, Tepmongkol S. Detection of subcentimeter metastatic cervical lymph node by ${ }^{18} \mathrm{~F}$-FDG PET/CT in patients with welldifferentiated thyroid carcinoma and high serum thyroglobulin but negative ${ }^{131} \mathrm{I}$ whole-body scan. Clin Nucl Med. 2012;37:561-567.

18. National Electrical Manufactures Association. NEMA standards publication NU 2-2012: performance measurements of positron emission tomographs. Rosslyn, VA: National Electrical Manufactures Association; 2012.

19. Soret M, Bacharach SL, Buvat I. Partial-volume effect in PET tumor imaging. J Nucl Med. 2007;48:932-945.

20. Mansor S, Pfaehler E, Heijtel D, Lodge MA, Boellaard R, Yaqub M. Impact of PET/CT system, reconstruction protocol, data analysis method and repositioning on PET/CT precision: an experimental evaluation using an oncology and brain phantom. Med Phys. 2017;44:6413-6424.

21. Adams MC, Turkington TG, Wilson JM, Wong TZ. A systematic review of the factors affecting accuracy of SUV measurements. AJR. 2010;195:310-320.

22. Weber WA, Gatsonis CA, Mozley PD, et al. Repeatability of ${ }^{18}$ F-FDG PET/CT in advanced non-small cell lung cancer: prospective assessment in 2 multicenter trials. J Nucl Med. 2015;56:1137-1143.

23. Kramer GM, Frings V, Hoetjes N, et al. Repeatability of quantitative whole-body ${ }^{18}$ F-FDG PET/CT uptake measures as function of uptake interval and lesion selection in non-small cell lung cancer patients. J Nucl Med. 2016;57:1343-1349.

24. Murata T, Miwa K, Miyaji N, et al. Evaluation of spatial dependence of point spread function-based PET reconstruction using a traceable point-like ${ }^{22} \mathrm{Na}$ source. EJNMMI Phys. 2016;3:26.

25. Snyder DL, Miller MI, Thomas LJ, Politte DG. Noise and edge artifacts in maximum-likelihood reconstructions for emission tomography. IEEE Trans Med Imaging. 1987;6:228-238.

26. Kidera D, Kihara K, Akamatsu G, et al. The edge artifact in point-spread function-based PET reconstruction at different sphere-to-background ratios of radioactivity. Ann Nucl Med. 2016;30:97-103.

27. Zhang L, Staelens S, Van Holen R, Verhaeghe J, Vandenberghe S. Characterization of the ringing artifacts in rotator-based reconstruction with Monte Carlobased resolution compensation for PET. Med Phys. 2010;37:4648-4660. 